\title{
Impact of consanguineous marriages and degrees of inbreeding on fertility, child mortality, secondary sex ratio, selection intensity, and genetic load: a cross-sectional study from Northern India
}

\author{
Mohd Fareed ${ }^{1}$, Mir Kaisar Ahmad ${ }^{2}$, Malik Azeem Anwar ${ }^{1}$ and Mohammad Afzal ${ }^{1}$
}

BACKGROUND: The aim of our study was to understand the relationship between consanguineous marriages and reproductive outcomes.

METHODS: A total of 999 families were recruited from five Muslim populations of Jammu region. Family pedigrees were drawn to access the family history and inbreeding status in terms of coefficient of inbreeding (F). Fertility, mortality, secondary sex ratio, selection intensity, and lethal equivalents were measured using standard methods.

RESULTS: The significant differences for gross fertility was found to be higher among inbred groups as compared to the unrelated families $(P<0.05)$ and higher mortality rates were observed among consanguineous families of all populations in comparison with the non-consanguineous family groups. Moreover, the prenatal and postnatal child mortality rates (i.e., U5MR and U18MR) have presented a persuasive increase with an upsurge in the homozygosity level. The mortality rate was found to be maximum among families with the highest value of coefficient of inbreeding (F). The selection intensity (SI) also showed inflations among families with respect to their increasing inbreeding coefficients. The greater values of lethal equivalents per gamete (LEs/gamete) were observed for autosomal inheritance in comparison with sex-linked inheritance.

CONCLUSION: Our conclusive assessment brings out the deleterious consequence of consanguineous marriages on reproductive outcomes.

$\mathbf{R}$ eproductive health or reproductive behavior refers to the diseases, disorders, and conditions related to the functioning of reproductive system (male or female) during all stages of life. The reproductive health problems among populations may also arise due to inequalities in the health related services and or schemes. Various factors such as consanguinity, socioeconomic status (SES), education level, employment, age, ethnicity, region, religion, and available resources affect the appropriate health services. The inadequacy of appropriate health services has been found to be more frequent among low socioeconomic and uneducated families (1).

Consanguineous marriages have been practised for thousands of years in many communities throughout the world. The prevalence of consanguinity varies among different countries, usually associated with different demographic features, such as religion, education, SES, geography and size of the area, isolation of the population, and living in rural or urban set up (2). Parental consanguinity has been associated with stillbirths, low birth weight, preterm delivery, abortion, infant and child mortality, congenital birth defects, cognitive impairments, cardiovascular risks, malformations, and several other complex disorders (3-10).

According to the United Nation (UN) estimates, more than 2.35 million children had died in India during 2005, which may account for more than $20 \%$ of all under- 5 deaths worldwide (11). The large disparities in child mortality and sex ratio in diverse regions of India has been reported previously (12). Fertility decline is also a major health issue, which has been strongly associated with socioeconomic conditions in most of the Asian and African countries (13). The fertility rates desperately vary across different states of India with an increase in the middle region, whereas low fertility rates have been reported in Southern and Northern most regions (14). Empirical research has been involved in explicating our focus toward the determinants of low fertility in contemporary India (15). Familial and sociodemographic characteristics such as early marriage, lesser birth intervals, domestic violence, gender preference, low spousal communication or poor marital relationship, and lack of decision-making regarding reproductive health choices also found to affect women's reproductive health (16).

Differential fertility and mortality patterns among human populations are known to be the driving key factors of natural selection. The determination of complete profile of reproductive fitness provides the opportunity to quantify the influence of selection processes in human evolutionary genetics.

'Department of Zoology, Aligarh Muslim University, Aligarh, India; ${ }^{2}$ Department of Clinical Biochemistry, Sher-I-Kashmir Institute of Medical Sciences (SKIMS), Srinagar, India. Correspondence: Mohammad Afzal (afzal1235@rediffmail.com)

Received 18 April 2016; accepted 7 July 2016; advance online publication 12 October 2016. doi:10.1038/pr.2016.177 


\section{RESULTS}

\section{Effect of Inbreeding and Sociodemographic Factors on Reproductive Behavior}

The characteristics of gross fertility among inbred and noninbred families has been presented in Supplementary Table S1 online. The gross fertility for male offspring was found to be higher among inbred groups as compared to non-inbred groups $(P<0.05)$. The inbreeding did not reveal any symbolic difference on live born female offspring. The gross fertility rates were found to lower among non-inbred mothers, i.e., below-45 $(3.18 \pm 0.07)$ and above-45 (4.92 \pm 0.09$)$ as compared to inbred families, i.e., below-45 (3.83 \pm 0.08$)$ and above-45 (5.66 \pm 0.12$)$ groups and the difference was found to be statistically significant $(P<0.05)$. Other sociodemographic factors such as residence, SES, population/ethnicity did not show any significant difference. The mothers above- 45 y of age have higher gross fertility as compared to those who did not reach the menopause stage (i.e., $<45 \mathrm{y}$ aged mothers).

Figure 1 presents the difference in under- 5 and under- 18 mortality rates (U5MR and U18MR) among inbred and non-inbred families. The male child mortality rates were found to be very high among inbred families as compared to non-inbred groups for all different categories $(P<0.05)$. The U5MR for female offspring did not show any significant difference between inbred and non-inbred groups; however, U18MR for female offspring presented somehow higher mean values among inbred groups than that of non-inbred groups of all different categories. The U18MR of inbred groups have displayed higher mortality rates for both male and female children as compared to non-inbred groups $(P<0.05)$. Moreover, male child mortality was found to be maximally increased among inbred families of all different backgrounds. These observations provide the evidence of cogent repercussion on child mortality due to inbreeding, whereas, sociodemographic factors behold negligible influence.

Figure 2 presents bar graph depicting the influence of inbreeding and other nongenetic factors on secondary sex ratio (SSR). We observed a significant increase in SSR among inbred groups as compared to the non-inbred groups for all different factors, depicting a persuasive effect of inbreeding on SSR, irrespective of the socioeconomic and sociodemographic factors. Greater values of selection intensities were observed among inbred groups than in non-inbred subjects for all different factors (Supplementary Table S2 online). Moreover, the SI values for male offspring were found to be higher in comparison with female groups. Overall, inbreeding presents a strong effect on SI than socioeconomic or sociodemographic factors.

Reproductive Behavior With Respect to Coefficient of Inbreeding The logistic regression analysis for different mortality groups (miscarriages, U5MR and U18MR) revealed the greater values of odds ratio (OR) and 95\% confidence interval (CI) with increasing levels of inbreeding (Table 1). Second cousin and first cousin once removed groups have presented nonsignificant $(P>0.05)$ increment in odds ratio for all different mortality groups with an exception for first cousin once removed, having significant impact over miscarriages (OR: 2.919, 95\% CI: 1.212, 7.033, $P=$
0.030 ). However, the first cousin (miscarriages, OR: $3.142,95 \%$ CI: 2.102, 4.698, $P<0.0001$; U5MR, OR: 1.478, 95\% CI: 1.168 , $1.871, P=0.0014$; U18MR, OR: 1.282 , 95\% CI: $1.062,1.548$, $P=0.011$ ) and double first cousin (miscarriages, OR: 5.948, 95\% CI: 3.639, 9.724, $P<0.0001$; U5MR, OR: 2.059, 95\% CI: 1.453 , 2.918, $P<0.0001$; U18MR, OR: 2.011, 95\% CI: 1.618, 2.665, $P<0.0001)$ groups with greater homozygosity levels showed many fold risks for prenatal and postnatal child mortality.

The child mortality rate in proportion to different degrees of inbreeding has been shown in Figure 3. The percent U5MR (Figure 3a) and U18MR (Figure 3b) tend to increase greatly among the groups with upsurge in the coefficient of inbreeding. The highest mortality rate was observed among the group having greater inbreeding coefficients (i.e., double first cousin, $F=0.125)$. The average child death per mother have markedly increased with respect to the increasing levels of inbreeding coefficients. In both the U5MR (Figure 3c) and U18MR (Figure 3d) groups, the highest average mortality was observed in case of double first cousin group (i.e., $\mathrm{F}=$ 0.125 ) and the least was observed for non-inbred group (i.e., $\mathrm{F}=0.00$ ). In short, inbreeding exhibit a detrimental impact over child mortality, with more serious risks associated with the increased homozygosity levels.

The pattern of gross fertility, SSR and SI with increasing values of coefficient of inbreeding has been displayed in Figure 4. The gross fertility was found to be systematically increased with the rise in the values of inbreeding coefficients (Figure 4a). These results provide an evidence for the wholesome effect of inbreeding on human fertility. The SSR increased maximally up to a level inbreeding coefficient group (i.e., the first cousin, $\mathrm{F}=0.0625$ ), however, further increase in the coefficient of inbreeding (i.e., the double first cousin, $F=0.125$ ) has led to the decline in SSR (Figure 4b). These findings suggest that the beneficial role of inbreeding is up to certain limits and beyond that the consequences may not be the favorable ones. The Crow's index (i.e., SI values) showed inflations with increase in the degrees of inbreeding (Figure 4c). The SI followed the trend: double first cousin group (0.3198) > first cousin $(0.2049)>$ first cousin once removed $(0.1712)>$ second cousin $(0.1624)>$ non-inbred $(0.161)$.

\section{Genetic Load due to Inbreeding}

Table 2 presents the autosomal and sex-linked (X-linked) genetic loads in terms of lethal equivalents per gamete (LEs/ gamete) among different inbred categories. For each of the inbreeding category, greater values of LEs/gamete were observed for autosomal inheritance in comparison with $\mathrm{X}$-linked ones. The estimates of genetic load (B/A ratio) due to inbreeding has been shown in Table 3 . The second cousin group, being lower in the category in terms of inbreeding coefficient, has presented a negative value $(-2.89)$. The first cousin (3.46) and double first cousin (5.95) showed persuasive increase in genetic load in proportion to the increasing inbreeding coefficients. However, first cousin once removed showed the highest value (10.62) than expected one, which might be due to the problem of lower sample size in that group because of infrequent marriage type than other matings. 


\section{Articles $\mid$ Fareed et al.}

a

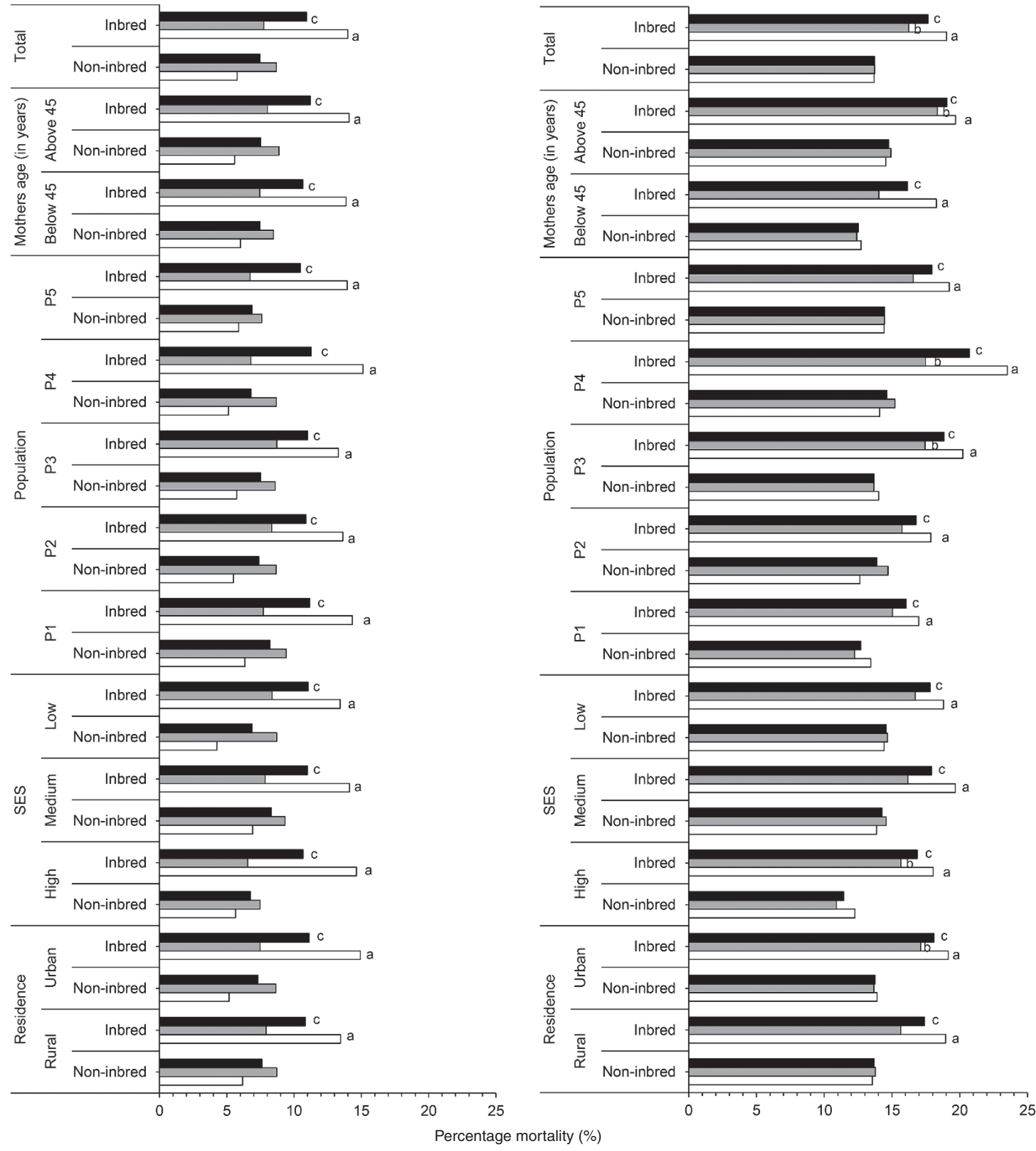

Figure 1. Effect of inbreeding and sociodemographic factors on child mortality. The bar graph presents (a) U5MR and (b) U18MR of male ( $\square$ ); female ( $\square$ ); and combined ( $\square$ ) groups among inbred and non-inbred families for different factors. The death rate (shown in percentage) is much prominent in U18MR as compared to that of U5MR group. In both, U5MR and U18MR groups, inbred families exhibit high child mortality rates than the unrelated ones for all different factors. ${ }^{a} P<0.05$ vs. non-inbred (male); ${ }^{b} P<0.05$ vs. non-inbred (female); ${ }^{c} P<0.05$ vs. non-inbred (combined) using ANOVA tests. U5MR, under- 5 mortality rate; U18MR, under-18 mortality rate; SES, socioeconomic status; P1, Gujjar and Bakarwal; P2, Mughal; P3, Malik; P4, Syed; P5, Khan.

\section{DISCUSSION}

In 2013, 6.3 million children died before reaching their fifth birthday; of which $99 \%$ of the deaths occurred in low- and middle-income countries. If the present global mortality rate continues, the estimate of U5MR will be approximately
4.4 million by 2030 (17). African countries show the highest mortality rate followed by Asian, South American, European, North American and Australian countries (18). In India, 40-79 deaths per 1,000 children has been reported due to different factors, nevertheless our study (i.e., from Jammu and Kashmir, 
a

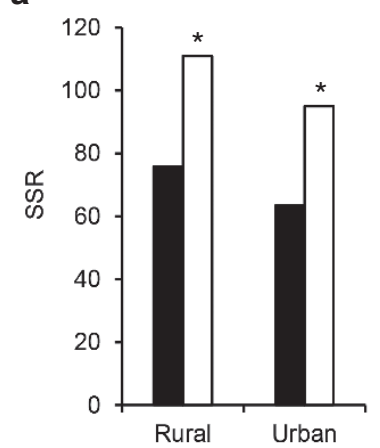

b

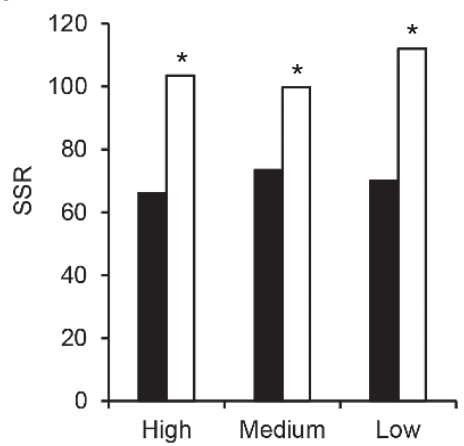

C

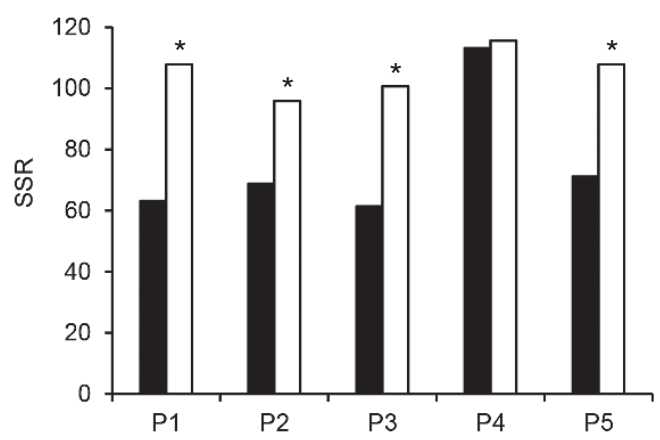

Figure 2. Effect of inbreeding on secondary sex ratio. The graph shows SSR differences in (a) residence, (b) socioeconomic status and (c) population for inbred $(\square)$ and non-inbred $(\square)$ families. The results show a significant increase in the SSR (number of males/100 females at birth) among inbred as compared to non-inbred groups for all different factors. ${ }^{*} P<0.01$ vs. non-inbred (using chi-square test). P1, Gujjar and Bakarwal; P2, Mughal; P3, Malik; P4, Syed; P5, Khan; SSR, secondary sex ratio.

Table 1. Logistic regression analysis comparing child mortality rates with different categories of inbreeding

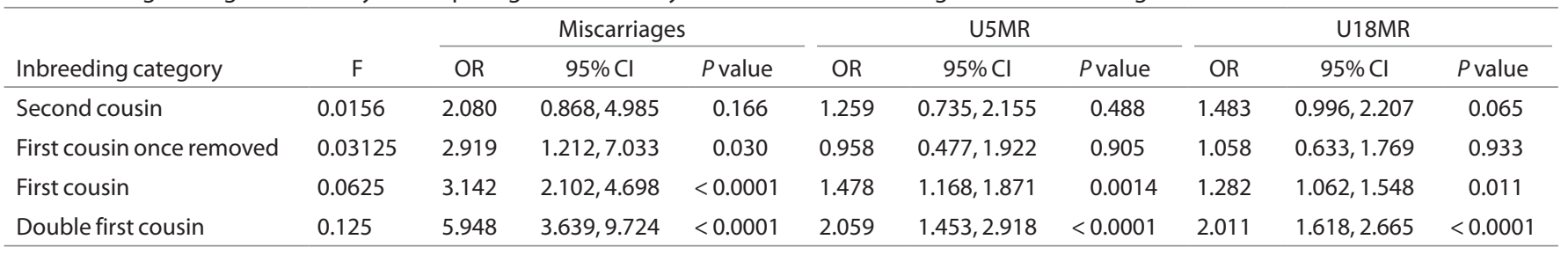

F, coefficient of inbreeding; OR, Odds ratio; Cl, Confidence interval (Lower bound, Upper bound). The odds ratio for inbred categories obtained using non-inbred as a control group for each mortality category.

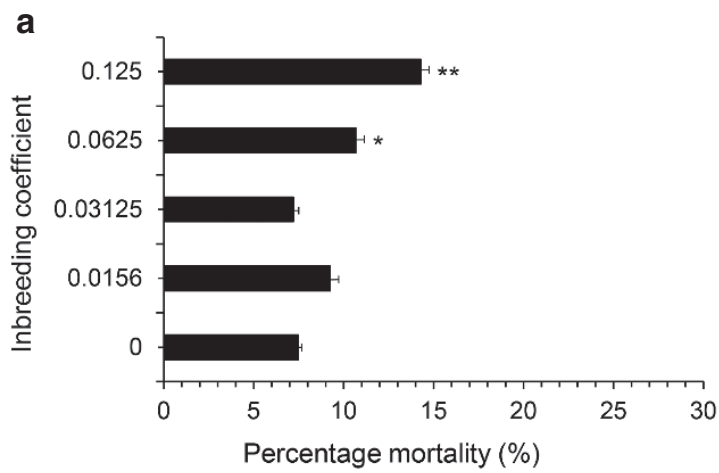

b

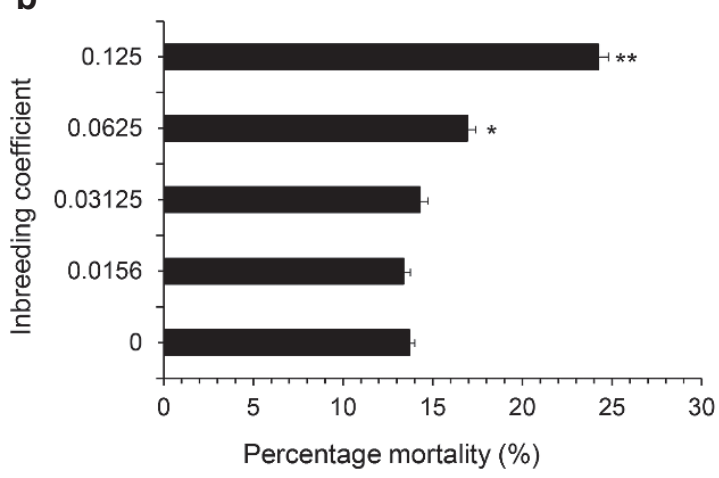

C

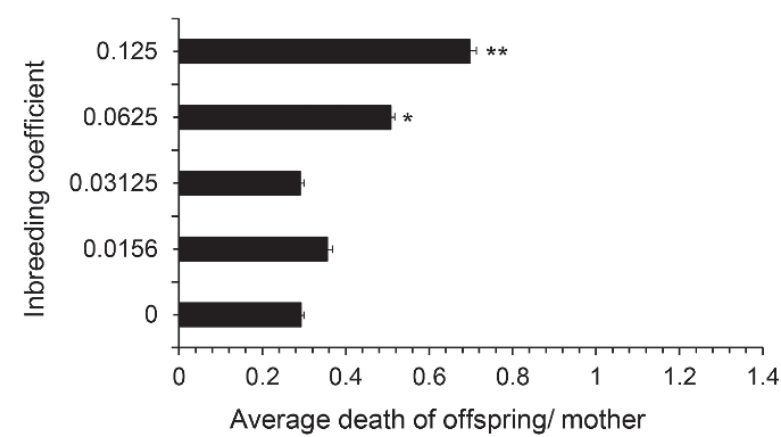

d

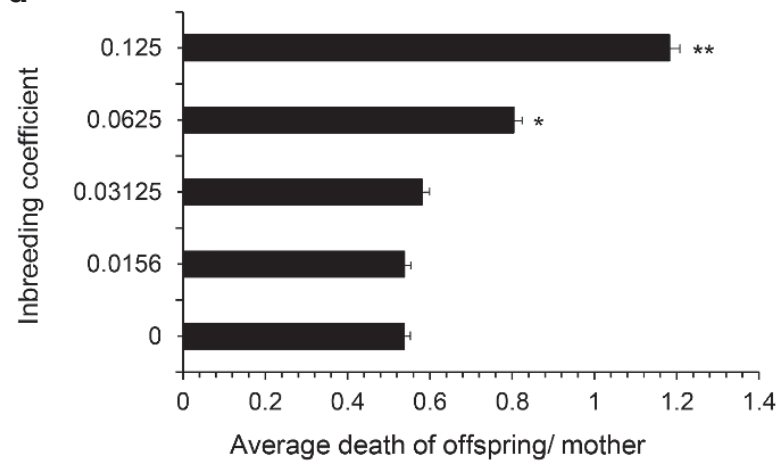

Figure 3. Child mortality with respect to the degree of inbreeding. The (a) U5MR and (b) U18MR groups showing percentage mortality rate and (c) U5MR and (d) U18MR presenting average mortality per mother in proportion to the coefficient of inbreeding. The percentage mortality and average death per mother for under- 5 and under-18 y groups shows inflations with the increasing inbreeding coefficients. ${ }^{*} P<0.05$ vs. non-inbred (i.e., $F=0.00$ ); ${ }^{* *} P<0.001$ vs. non-inbred $(F=0.00)$ using ANOVA test. U5MR, under-5 mortality rate; U18MR, under-18 mortality rate; $F$, inbreeding coefficient. 


\section{Articles | Fareed et al.}

a

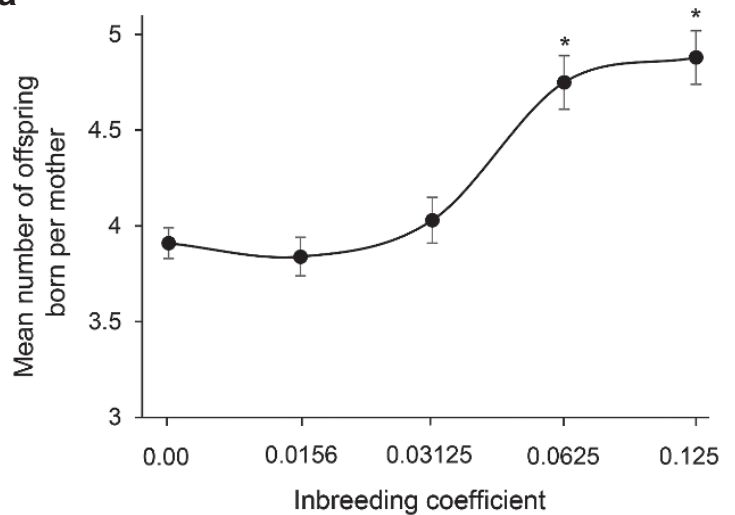

C

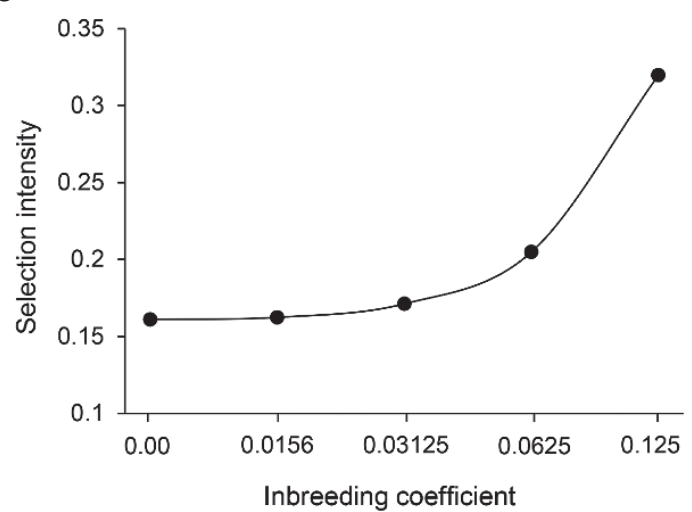

b

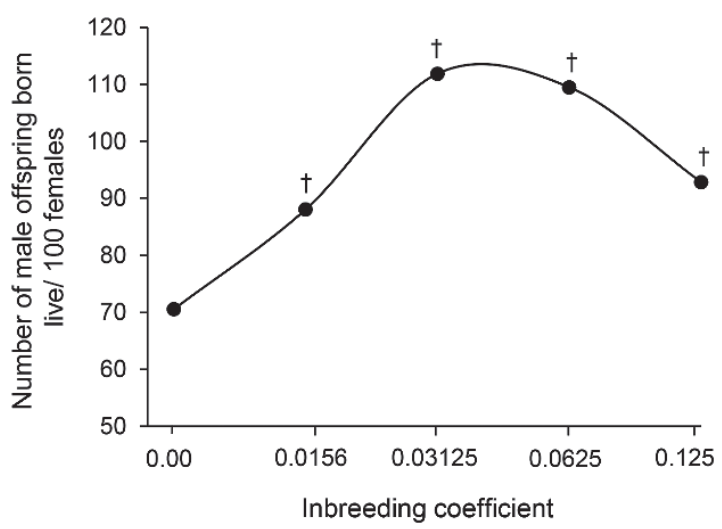

Figure 4. Reproductive behavior with respect to increasing level of homozygosity. Line graph presents the (a) gross fertility, (b) secondary sex ratio, and (c) selection intensity patterns in proportion to the coefficient of inbreeding. The gross fertility shows upturn with increase in the coefficient of inbreeding (from non-inbred to double first cousin). The SSR markedly increases up to a level with increase in the coefficient of inbreeding (i.e., the first cousin, $F$ $=0.0625$ ), however, further increase in inbreeding coefficient (i.e., the double first cousin, $F=0.125$ ) leads to decline in SSR values. The selection intensity trend in each category also present inflations in proportion to the degree of inbreeding (i.e., coefficient of inbreeding). ${ }^{*} P<0.05 \mathrm{vs}$. non-inbred (i.e., $\mathrm{F}=$ 0.00 ) using student's t-test. ${ }^{+} P<0.001$ vs. non-inbred (i.e., $\mathrm{F}=0.00$ ) using chi-square test. $S S R$, secondary sex ratio; $\mathrm{F}$, inbreeding coefficient.

Table 2. Genetic load (LEs/gamete) due to inbreeding

\begin{tabular}{|c|c|c|c|c|}
\hline \multirow[b]{2}{*}{ Inbreeding type } & \multicolumn{2}{|c|}{ Autosomal } & \multicolumn{2}{|c|}{ X-linked } \\
\hline & $\mathrm{F}$ & $\begin{array}{l}\text { LEs/ } \\
\text { gamete }\end{array}$ & $\mathrm{F}$ & $\begin{array}{c}\text { LEs/ } \\
\text { gamete }\end{array}$ \\
\hline Second cousin & 0.0156 & 0.8013 & 0.04779 & 0.68842 \\
\hline First cousin once removed & 0.03125 & 2.2048 & 0.05769 & 0.56335 \\
\hline First cousin & 0.0625 & 0.5984 & 0.06624 & 0.10114 \\
\hline Double first cousin & 0.125 & 1.0648 & 0.1674 & 0.24133 \\
\hline Total & $0.0656225^{\mathrm{a}}$ & 0.78479 & $0.079998^{\mathrm{a}}$ & 0.167504 \\
\hline
\end{tabular}

a Representing the average coefficient of inbreeding $(\alpha), F=$ Coefficient of inbreeding, LES $=$ Lethal equivalents.

Northern India) provides a comprehensive report for the first time on the fertility and mortality patterns in relation to inbreeding and sociodemographic factors.

In our study, the sociodemographic factors such as residence, SES, population, and ethnicity seems to be insignificant, revealing the fact that different populations are confined to the same geographical, socio-cultural and environmental constraints. Our findings depict a persuasive influence of inbreeding on gross fertility with elevated levels of fertility being observed
Table 3. Estimates of genetic load (B/A ratio) due to inbreeding

\begin{tabular}{lcccc}
\hline & \multirow{2}{*}{$\begin{array}{c}\text { Coefficient of } \\
\text { inbreeding (F) }\end{array}$} & \multicolumn{3}{c}{ Genetic load estimates } \\
\cline { 3 - 5 } Inbreeding types & 0.00 & 0.147689 & & \\
\hline Non-inbred & & & & \\
Inbred & 0.0156 & -0.42692 & -2.89 \\
Second cousin & 0.03125 & 1.56902 & 10.62 \\
First cousin once removed & 0.0625 & 0.51232 & 3.46 \\
First cousin & 0.125 & 0.87983 & 5.95 \\
\hline Double first cousin & $0.0671^{\mathrm{a}}$ & & 0.63779 & 4.32 \\
\hline Pooled (Total inbred) & & & &
\end{tabular}

aRepresenting the average coefficient of inbreeding $(\alpha)$. The value of " $\mathrm{A}$ " is same for all inbred categories.

among inbred groups as compared to the non-inbred families. Importantly, the increment in gross fertility rate was mainly due to male offspring as compared to female child births. This can explain the phenomenon of sex-based selection on fertility due to genetic component (i.e., inbreeding), which still remains a question that needs to be investigated further. Increased fertility among inbred (consanguineous) families has also been reported by other researchers (19-21). This increased fertility 
is usually a consequence of reproductive compensation due to high mortality among inbred families $(22,23)$.

Many epidemiological studies support the relationship between inbreeding and increased child mortality (6,24-27). Our study presents the elevated levels of child mortality (U5MR and U18MR) among inbred groups of all the populations in comparison with non-inbred groups. Moreover, the frequency of male child mortality was found to be much higher among inbred families. We have found inflations in postnatal mortality in proportion to the increasing degrees of inbreeding. The highest mortality rate was found among double first cousin group, with male child mortality being more predominant among inbred families. However, sex-specific mortality and precise lethal genes still need to be explored.

The downturn of SSR is also a major health burden, associated with genetic or socioeconomic factors. Several studies have pointed out different factors influencing sex ratio among humans such as higher male child mortality, maternal education, economic and political disruption, malnutrition, hormonal imbalance, and regional or geographical disparities. A few studies on SSR in relation to inbreeding have been made in the recent past (28). Our results provide a persuasive effect of inbreeding on SSR, irrespective of socioeconomic and sociodemographic factors. More interestingly, the SSR upsurge was observed from non-inbred group to the first cousin group, afterwards the trend declined for double first cousins. We also observed a cogent effect of inbreeding on Crow's index (i.e., SI). The SI values found to escalate and expand with the rise in the coefficient of inbreeding and the maximum value was noticed for the highest degree of inbreeding. The highest SI value was observed for double first cousin group (0.3198), whereas SI values for all other groups ranged between non-inbred (0.161) and first cousin (0.2049) group. However, these values are considered as low (29), indicating that the mutation has a low chance of being eliminated through natural selection. As defined by Crow, the index of total selection intensity approaches zero, there will be fewer changes in the genetic makeup of a population. A previous study from Uttar Pradesh, North India, has reported lower selection intensities among populations of consanguineous groups in comparison with the nonconsanguineous ones (30). However, we did not find any detailed study equating selection intensity with different degrees of inbreeding. Thus, our approach adds strength to this study in exploring the interaction of natural selection and inbreeding.

The estimated genetic load in terms of lethal equivalents per gamete (LEs/gamete) for autosomal and sex-linked (X-linked) alleles represent intriguing findings. In each of the inbreeding category, greater values of LEs/gamete were observed for autosomal inheritance in comparison with X-linked ones, confirming the fact that homozygosity of autosomal recessive genes has a deleterious consequence leading to high genetic load. One of the most recent studies based on autozygosity mapping and whole-exome sequencing has identified the role of embryonically lethal genes in consanguineous families (31).

Based on the current findings, increased mortality among inbred group shows a longitudinal impact over selection intensity and genetic load. The inflations in the fertility, SSR and SI among inbred groups is directly proportional to their mortality rates, which somehow explain the strong effect of natural selection, trying to restore the reproductive loss due to increased mortality. Despite having some influence of residence, culture, literacy and social/or economical stress on reproductive health, the genetic factor (i.e., inbreeding/consanguinity) holds the most preeminent effect. The social impacts may result into malnutrition, low health status and disease risk in some communities/or individuals who are socioeconomically weak. However, irrespective of socioeconomic backgrounds, inbreeding acts directly on human genome to expose the disease susceptible genes or/ even expression of lethal genes causing greater impact on human health and disease.

\section{Conclusion}

Our study provides the substantial effect of inbreeding on reproductive performance in comparison with nongenetic factors. The miscarriages, under-5 and under- 18 child mortality rates display maximum frequency with respect to the increasing degree of inbreeding. The increase in the SSR and SI was much pronounced among inbred families in comparison with non-inbred group and greater values of lethal equivalents for autosomal inheritance in comparison with X-linked was also observed, thereby, establishing the evidence of homozygosity of autosomal recessive genes to cause a deleterious effect, leading to the increased child mortality. Furthermore, the role of sex and specific lethal genes in child mortality still needs to be investigated, which may be attempted in near future.

Our study provides a direct roadmap for health care providers and health policy makers to make people aware of harmful consequences of consanguinity. Such a rich evidence-based guidelines regarding inbreeding pursuance would better help families for premarital counseling.

\section{METHODS}

\section{Ethical Approval}

The study was approved by the Institutional Ethics Committee of Jawaharlal Nehru Medical College (JNMC), Aligarh Muslim University, India. The informed written consent from the participants was also obtained that were involved in our study.

\section{Parental Background}

The parental background characteristics were assessed in two dimensions: residence (rural or urban) and SES (low, medium, and high) and the Indian adapted version of SES scale was used (8). The parental SES was based on three main domains: education, occupation and household income. The SES was assessed for both parents (i.e., mother and father) and mean score was considered for complete parental SES. On the basis of scores, we categorised SES into three classes: "26-29" as high, " $11-25$ " as medium and " $<10$ " as low. All information was recorded in a standardised questionnaire.

\section{Population and Study Design}

The Muslim populations were selected in our survey from Rajouri and Poonch Districts of Jammu and Kashmir, India. The incidence of consanguineous marriages ranged from 35 to $50 \%$ among these populations $(7,8)$. In order to select the subjects, a preliminary visit to the areas was made and it was found that more than $75 \%$ (approximately) of population lives in villages that might be due to the topographical feature of the area (i.e., hilly region). We also observed the cultural beliefs related with marriages among different populations. 


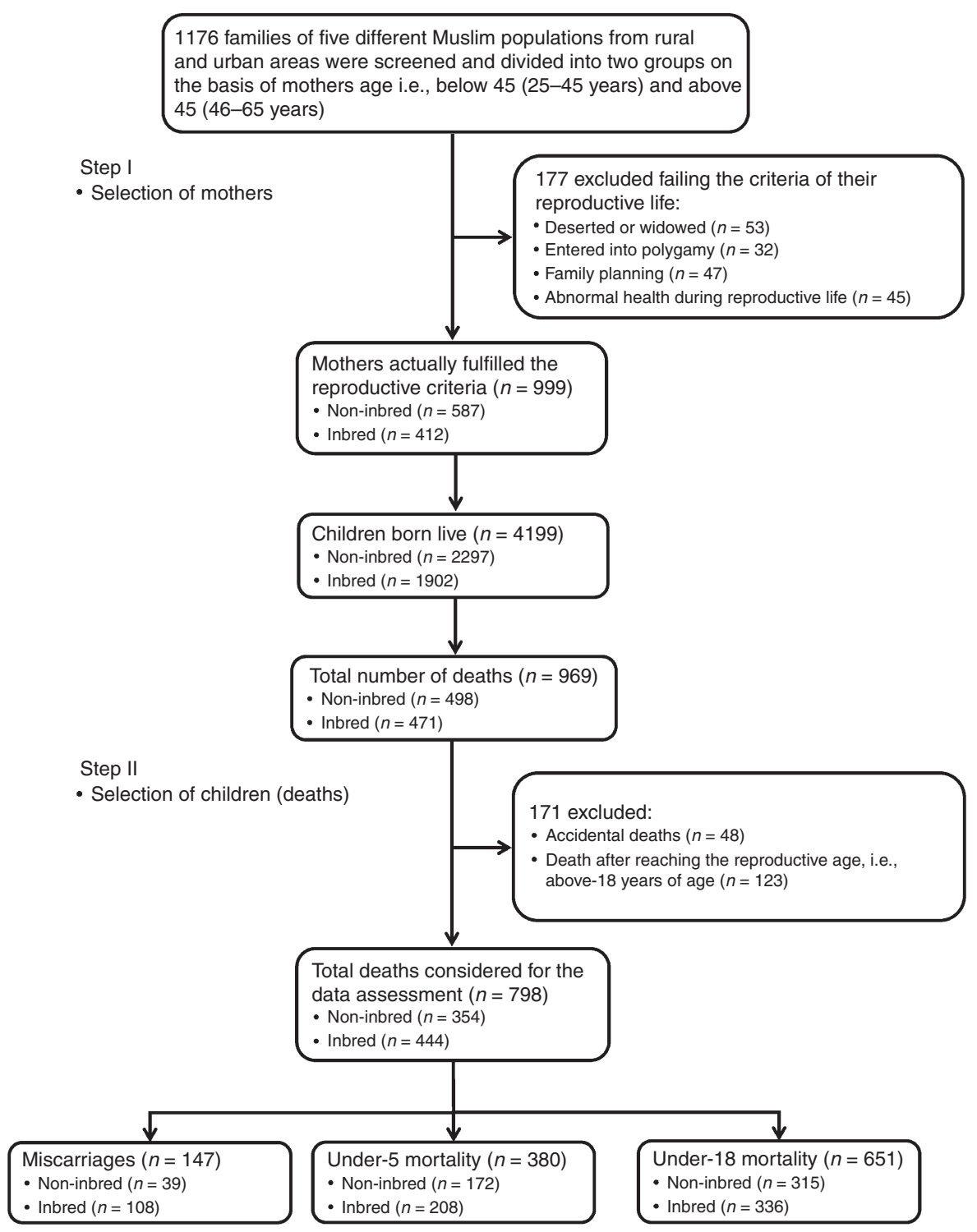

Figure 5. Study design. Flowchart depicting the steps involved in recruitment process.

The structure of caste and tribes were very rigid, favoring marriages among close relatives, which in turn increases the homozygosity level due to inbreeding.

The study was conducted during April 2014 through January 2015 and a total of 999 families were recruited from five Muslim populations viz., Gujjar and Bakarwal $(n=274)$, Mughal $(n=223)$, Malik $(n=$ $185)$, Syed $(n=121)$, and Khan $(n=196)$. Figure 5 depicts the sample size and steps involved in the recruitment process of study design. Care was taken to choose only those mothers who were not deserted or widowed, did not practice polygamy, did not use any family planning device and maintained a normal health during their reproductive life.

\section{Pedigree Analysis}

Genealogical information (i.e., pedigree analysis) up to five generations back (volunteered by the subjects) helped in ascertaining the consanguinity pattern of their marriage that helped in determining the child's inbreeding status. The information provided by the subjects was cross checked by seeking help from elder members of the family. In case of ambiguity, such data was omitted.

Wright's path relationship method was used for calculating the coefficient of inbreeding $(F)$ for different mating types in the order: double first cousin $(\mathrm{F}=0.125)>$ first cousin $(\mathrm{F}=0.0625)>$ first cousin once removed $(\mathrm{F}=0.03125)>$ second cousin $(\mathrm{F}=0.0156)$.
In nonconsanguineous families, the coefficient of inbreeding corresponds to zero $(\mathrm{F}=0.000)(32)$.

\section{Measures and Procedures}

i. Fertility: Fertility (live born per mother) was determined for children of both male and female sexes separately and cumulatively as well. The gross fertility is defined as the average number of offspring born live per mother. For mothers above- 45 $y$ of age (i.e., who have completed their reproductive life) the gross fertility may be termed as total fertility rate (TFR). Cases with contraceptive histories and medical termination of pregnancy (MTP) were excluded.

ii. Mortality: The mortality rate of the offspring was analyzed under two main groups: under-5 mortality rate (U5MR) and under-18 mortality rate (U18MR). The miscarriages $(n=147)$ among different groups were observed as, non-inbred $(n=39)$, second cousin $(n=06)$, first cousin once removed $(n=06)$, first cousin $(n=66)$ double first cousin $(n=30)$. The accidental deaths and after the reproductive age, (i.e., above- 18 y of age) were excluded. For calculating the selection intensity, U18MR was used.

iii. Secondary sex ratio: The secondary sex ratio is the ratio of males to females at birth in a population. The sex of the children born 
alive or dead was noted and the number of boys per hundred girls born was then calculated.

iv. Selection Intensity (SI): Natural selection is one of the basic mechanisms of evolution, eliminating lethal mutations from affected populations. Crow (29) showed that the effectiveness of natural selection in a population can be measured using estimates of differential fertility and differential child mortality. The proposed index of total selection intensity is also known as the index of opportunity for selection. If the index of total selection intensity approaches zero, there will be fewer changes in the genetic makeup of a population. Crow's index has been widely used for quantitative estimation of relative biological fitness of small human populations. The index of selection intensity was calculated using formula as follows.

$$
I=\operatorname{Im}+\frac{I_{f}}{P_{s}}
$$

where, $\operatorname{Im}=\frac{P_{d}}{P_{s}}, I_{f}=\frac{V_{f}}{(\bar{X})^{2}}$ and $P_{s}=1-P_{d}$

Here, "I" is the index of total selection, "Im" is the index of selection due to mortality, ' $\mathrm{I}_{\mathrm{f}}$ ' is the index of selection due to fertility, $\overline{\mathrm{X}}$ is the mean number of live births per woman until her attaining the age of $45 \mathrm{y}$ and above, i.e., at menopause, " $\mathrm{V}_{\mathrm{f}}$ " is the variance in the number of live births due to fertility and " $\mathrm{P}_{d}$ " is the death before reaching the age of $18 \mathrm{y}$.

v. Inbreeding load: The "inbreeding load" is defined as the rate at which fitness declines with increased inbreeding coefficient (which determines the proportion of homozygous loci in the genome). Several approaches have been used to quantify the inbreeding depression or inbreeding load. Lethal-equivalent are the alleles likely to contribute to the recorded rates of fetal or infant mortality in the cohort when offspring inherit these variants in a homozygous state. The genetic load in terms of lethal equivalents (LEs) per gamete for autosomal and sexlinked inheritance in different inbred categories was determined using the formula (33):

LEs $/$ gamete $=\frac{\text { Mean difference in } \% \text { mortality }(\text { Non-inbred }- \text { Inbred }) / 100}{\text { Inbreeding coefficient }}$

Crow and Kimura (34) method for determining the inbreeding coefficient (F) for sex-linked genes was used in our study. The estimates of genetic load due to inbreeding (B/A ratio) was calculated from "A" and " $\mathrm{B}$ " values, as follows:

$$
\begin{aligned}
& A=1-S_{1} \\
& B=\frac{S_{1}-S_{2}}{F}
\end{aligned}
$$

where, $S_{1}$ and $S_{2}$ represent the ratio of children surviving for noninbred and inbred categories respectively. "A" and "B" represent the death ratio in non-inbred and inbred groups respectively.

\section{Statistical Analysis}

Statistical analysis was conducted using SPSS software 17.0 version (SPSS, Chicago, IL) GraphPad InStat 3.0 (San Diego, CA), Origin 8.0 (Origin Lab Corporation, Northampton, MA), XLSTAT 2015 for windows version 17.1.02 (Addinsoft, Paris, France). The means \pm SD between inbred from non-inbred (i.e., control) groups, were tested using student's t-test. Logistic regression analysis (odds ratio, 95\% confidence interval) was used for comparing child mortality rates with different categories of inbreeding. Analysis of variance (ANOVA) and chi-square $\left(\chi^{2}\right)$ test were also used to determine the significant difference. Statistical significance was checked at $P<0.05, P<0.01$,
$P<0.001$ and $P<0.0001$. The average coefficient of inbreeding $(\alpha)$ was calculated as follows:

$$
\text { Average coefficient of inbreeding }(\alpha)=\frac{\begin{array}{l}
\mathrm{n} \times 0 \cdot 125+\mathrm{n} \times 0 \cdot 0625+\mathrm{n} \times 0 \cdot 03125+ \\
\mathrm{n} \times 0 \cdot 0156+\ldots .(\mathrm{n} \times 0 \cdot 000)
\end{array}}{\mathrm{N}}
$$

where " $\mathrm{n}$ " indicates the number of individuals multiplied with inbreeding coefficients (F) for each of the inbreeding category. The F-value $=0.000$, indicates the non-inbred individuals and " $\mathrm{N}$ " is the sum total of all individuals.

\section{SUPPLEMENTARY MATERIAL}

Supplementary material is linked to the online version of the paper at http:// www.nature.com/pr

\section{ACKNOWLEDGMENTS}

We are thankful to the Chairman, Department of Zoology, AMU, Aligarh for providing necessary laboratory facilities for this work. Thanks are due to the participants involved in this study, without whose cooperation the work could not have been completed.

\section{STATEMENT OF FINANCIAL SUPPORT}

This study was supported by The Council of Scientific and Industrial Research (CSIR), New Delhi, India, for the award of Senior Research Fellowship (File No. 9/112(0510)2K14-EMR-I) to the first author. The funder had no role in the design, conduct, or analysis of the trial.

Disclosure: None of the authors have any conflicts of interest to disclose.

\section{REFERENCES}

1. Hall KS, Moreau C, Trussell J. Determinants of and disparities in reproductive health service use among adolescent and young adult women in the United States, 2002-2008. Am J Public Health 2012;102:359-67.

2. Bener A, Abdulrazzaq YM, al-Gazali LI, Micallef R, al-Khayat AI, Gaber T. Consanguinity and associated socio-demographic factors in the United Arab Emirates. Hum Hered 1996;46:256-64.

3. Afzal M. Consequences of consanguinity on cognitive behavior. Behav Genet 1988;18:583-94.

4. Badaruddoza, Afzal M. Inbreeding depression and intelligence quotient among north Indian children. Behav Genet 1993;23:343-347.

5. Badaruddoza, Afzal $\mathrm{M}$, Akhtaruzzaman. Inbreeding and congenital heart diseases in a North Indian population. Clin Genet 1994;45: 288-291.

6. Tadmouri GO, Nair P, Obeid T, Al Ali MT, Al Khaja N, Hamamy HA. Consanguinity and reproductive health among Arabs. Reprod Health 2009;6:17.

7. Fareed M, Afzal M. Estimating the inbreeding depression on cognitive behavior: a population based study of child cohort. PLoS One 2014;9:e109585.

8. Fareed M, Afzal M. Evidence of inbreeding depression on height, weight, and body mass index: a population-based child cohort study. Am J Hum Biol 2014;26:784-95.

9. Fareed M, Afzal M. Increased cardiovascular risks associated with familial inbreeding: a population-based study of adolescent cohort. Ann Epidemiol 2016;26:283-92.

10. Bittles AH, Black ML. Evolution in health and medicine Sackler colloquium: Consanguinity, human evolution, and complex diseases. Proc Natl Acad Sci USA 2010;107 Suppl 1:1779-86.

11. Black RE, Cousens S, Johnson HL, et al.; Child Health Epidemiology Reference Group of WHO and UNICEF. Global, regional, and national causes of child mortality in 2008: a systematic analysis. Lancet 2010;375:1969-87.

12. Jha P, Kumar R, Vasa P, Dhingra N, Thiruchelvam D, Moineddin R. Low female-to-male sex ratio of children born in India: national survey of 1.1 million households. Lancet 2006;367:211-8.

13. Majumder N, Ram F. Explaining the role of proximate determinants on fertility decline among poor and non-poor in Asian countries. PLoS One 2015;10:e0115441. 


\section{Articles | Fareedet al.}

14. Census of India. Estimates of Fertility Indicators. Vital Statistics of India. Government of India. 2013:48.

15. Dharmalingam A, Rajan S, Morgan SP. The determinants of low fertility in India. Demography 2014;51:1451-75.

16. D'Souza MS, Karkada SN, Somayaji G, Venkatesaperumal R. Women's well-being and reproductive health in Indian mining community: need for empowerment. Reprod Health 2013;10:24.

17. Liu L, Oza S, Hogan D, et al. Global, regional, and national causes of child mortality in 2000-13, with projections to inform post-2015 priorities: an updated systematic analysis. Lancet 2015;385:430-40.

18. UNICEF. Levels \& Trends in Child Mortality. Report. Estimates developed by the UN Inter-agency Group for Child Mortality Estimation. New York 2013:1-30.

19. Fuster V. Inbreeding pattern and reproductive success in a rural community from Galicia (Spain). J Biosoc Sci 2003;35:83-93.

20. Helgason A, Pálsson S, Gudbjartsson DF, Kristjánsson T, Stefánsson K. An association between the kinship and fertility of human couples. Science 2008;319:813-6.

21. Weller M, Santos S. A positive association between consanguinity and fertility in communities of Paraíba, Northeast Brazil. Ann Hum Biol 2013;40:527-30.

22. Schull WJ, Neel JV. The effects of parental consanguinity and inbreeding in Hirado, Japan. V. Summary and interpretation. Am J Hum Genet 1972;24:425-53.

23. Ober C, Hyslop T, Hauck WW. Inbreeding effects on fertility in humans: evidence for reproductive compensation. Am J Hum Genet 1999;64:225-31.
24. Khlat M, Khoury M. Inbreeding and diseases: demographic, genetic, and epidemiologic perspectives. Epidemiol Rev 1991;13:28-41.

25. Saha N, Hamad RE, Mohamed S. Inbreeding effects on reproductive outcome in a Sudanese population. Hum Hered 1990;40:208-12.

26. Shawky RM, Elsayed SM, Zaki ME, El-din SMN, Kamal FM. Consanguinity and its relevance to clinical genetics. Egypt J Med Hum Genet 2013;14:157-164.

27. Hosseini-Chavoshi M, Abbasi-Shavazi MJ, Bittles AH. Consanguineous marriage, reproductive behaviour and postnatal mortality in contemporary Iran. Hum Hered 2014;77:16-25.

28. Bittles A. Consanguinity and its relevance to clinical genetics. Clin Genet 2001;60:89-98.

29. Crow JF. Some possibilities for measuring selection intensities in man. Hum Biol 1958;30:1-13.

30. Aarzoo SS, Afzal M. Reproductive fitness and selection intensity among Muslims of North India. J Hum Ecol 2006;19:107-112.

31. Shamseldin HE, Tulbah M, Kurdi W, et al. Identification of embryonic lethal genes in humans by autozygosity mapping and exome sequencing in consanguineous families. Genome Biol 2015;16:116.

32. Wright S. Coefficients of inbreeding and relationship. Am Nat 1922; 330-338.

33. Chakraborty R, Chakravarti A. On consanguineous marriages and the genetic load. Hum Genet 1977;36:47-54.

34. Crow JF, Kimura M. An Introduction to Population Genetics Theory. Harper and Row, New York, USA 1970. 